\title{
Smallholder farmers' social networks and resource-conserving agriculture in Ghana: a multicase comparison using exponential random graph models
}

\author{
Hanson Nyantakyi-Frimpong ${ }^{1}$, Petr Matouš ${ }^{2}$ and Marney E. Isaac ${ }^{3,4}$
}

\begin{abstract}
We examined what type of information network structures lie within rural cooperatives and what these structures mean for promoting resource-conserving agriculture. To better understand whether and how environmental outcomes are linked to these microlevel social relations or network structures, we quantified individual farm- and community-level biomass accumulation and carbon stocks associated with the adoption of agroforestry, a set of farming techniques for climate change mitigation, adaptation, and resilience. We also collected social network data on individual farmers across five communities. This empirical evidence was derived from primary fieldwork conducted in the Ghanaian semideciduous cocoa (Theobroma cacao)-growing region. This data set was examined using standard network analysis, combined with exponential random graph models (ERGMs). The key findings suggest that farmers with more biomass accumulation from the adoption of agroforestry practices also tend to be popular advisers to their peers at the local level. Presumably, farmers seek peers who demonstrate clear signs of achieving successful land management goals. Using ERGMs, we also show that commonly observed individual-level results might not scale to the collective level. We discuss how our individual-scale findings could be leveraged to foster farmer-to-farmer social learning and knowledge exchange associated with resource-conserving agricultural practices. However, we also highlight that effective whole networks, such as cooperative collectives in these communities, remain elusive.
\end{abstract}

Key Words: agroforestry; climate change adaptation and mitigation; ERGMs; resource-conserving agriculture; social network analysis; Theobroma cacao

\section{INTRODUCTION}

African agriculture is under significant threat from global environmental change. Although the region emits just 3\% of the world's greenhouse gases (Tubiello et al. 2013), it will be affected more gravely than anywhere else, by even the smallest rise in global temperatures (Niang et al. 2014). One of Africa's agricultural sectors under highest threat from climate change is the food and cash crop sector. International climate scientists expect that by the year 2050, African crop production will decrease by as much as $22 \%$ because of climate variability and change (Sultan et al. 2013, Niang et al. 2014). Food and cash crop productivity will be mired by increasingly truncated growing seasons, erratic rains, recurrent droughts, heat stress, and dry, as well as low-fertility, soils (Torquebiau 2016). Variability in temperatures might also affect the proliferation and spread of invasive pests and crop diseases, with devastating impacts on yields, food prices, and food security (Biber-Freudenberger et al. 2016, Torquebiau 2016).

There is ample evidence suggesting that a substantial part of the potential yield loss could be averted by using innovative, resourceconserving, and proenvironmental farming techniques, including no-till farming, crop-livestock integration, agroforestry, intercropping, and other conservation agricultural practices (Dewees et al. 2011, Mbow et al. 2014, Altieri et al. 2015, Govorushko 2016, Kim et al. 2016, Kongsager et al. 2016, Nyantakyi-Frimpong et al. 2017). We focus on one of these practices: agroforestry. Broadly, agroforestry is defined as "any practice to purposefully grow trees together with crops, or animals for a variety of benefits and services" (Kim et al. 2016:66). As a resource-conserving practice, agroforestry diversifies agricultural systems and provides both economic and ecological benefits
(Dewees et al. 2011, Mbow et al. 2014, Martin and Isaac 2015, Govorushko 2016). As a type of agroecosystem, agroforestry contributes to pest control, nitrogen fixation, enhanced soil stability, and microclimate modifications (Malézieux et al. 2009, Munroe and Isaac 2014, Kim et al. 2016). Moreover, agroforestry has one of the greatest carbon sequestration potentials across land use types, through enhanced fine root production, rhizodeposition, and woody tissue carbon storage (Kim et al. 2016). Thus, trees on farms simultaneously support both above- and belowground ecosystem services, making agroforestry not only a major form of climate adaptation, but also a mitigation strategy (Mbow et al. 2014, Govorushko 2016, Kongsager et al. 2016).

Currently, there is a growing interest in investing in agroforestry systems in Africa (Dewees et al. 2011). A vast array of agricultural technology adoption literature has examined factors affecting farmers' tree planting decisions. These studies have demonstrated that the decision to integrate trees into farming systems is shaped by land tenure, access to labor, farm size, capital, and level of education (Nkamleu and Manyong 2005, Gyau et al. 2012, Mbow et al. 2014). Although we have some key research assessing the role of cooperation (Levy and Lubell 2018) and organizational membership (Rico García-Amado et al. 2012) in agricultural networks, what still remains poorly understood is the role of rural cooperatives, their network structures, and the consequences of these structures for agroforestry and other resource-conserving agricultural practices. Increasingly, formal and informal networks and their interaction have been highlighted as key variables in the adoption and success of community-based and agricultural resource management (Bodin and Tengo 2012, Isaac 2012, Isaac and Matous 2017). Understanding and optimizing these networks

${ }^{1}$ Department of Geography and the Environment, University of Denver, Colorado, USA, ${ }^{2}$ University of Sydney, Australia, ${ }^{3}$ Department of Physical and Environmental Sciences and the Centre for Critical Development Studies, University of Toronto Scarborough, Ontario, Canada, ${ }^{4}$ Department of Geography, University of Toronto, Ontario, Canada 
within established and active cooperatives will undoubtedly reinforce the goals of cooperative action and stimulate successful outcomes in the face of environmental and social change.

Our main purpose is to address this knowledge gap through original research in a cocoa (Theobroma cacao)-growing region in Ghana, West Africa. More specifically, we are interested in understanding the structural pattern of information sharing and advice seeking among rural cooperative farmers and what these structural relations mean for agroecosystem management. We ask two primary research questions:

1. What information network structures or motifs lie within rural cooperatives?

2. What structural, demographic, and/or environmental attributes best predict the formation of these information networks?

We examine these questions with data from farmers who are part of the same cooperative organization but reside in five geographically disparate locations. Answering these questions in particular requires multiple data points, and we use data encompassing farmers' social networks, demographics, farm-level biophysical characteristics, and community-level environmental outcomes from five sites.

Methodologically, we use observed network data to answer both questions but two different statistical approaches. The first question was addressed using standard network analysis and exponential random graph models (ERGMs; Robins, Pattison, et al. 2007, Robins, Snijders, et al. 2007, Wang et al. 2013, Dickison et al. 2016, Wang et al. 2016) to analyze endogenous mechanisms within multiple networks. The second research question was addressed by using biophysical data from the field and ERGMs. Initially developed around the late 1990s (Pattison and Wasserman 1999), ERGMs have gained popularity in the last few years as an advancement of, and to address limitations associated with, conventional methods in social network analysis (Robins, Pattison, et al. 2007, Robins, Snijders, et al. 2007). Standard network approaches, although widespread as an approach to statistically analyze observed network data, have limitations such as an inability to examine tie formation at the network level and account for potential cross dependencies and emergent network structures (Wang et al. 2013). ERGMs address these limitations. We use standard network analysis to show the direct statistical relationship between actor covariates and their links. We use ERGMs to control for the endogenous network tendencies. Because we focus on multiple networks, ERGMs in conjunction with standard social network analysis offer an invaluable tool because of their ability to examine multicase comparisons (e.g., Brennecke and Rank 2016).

\section{The farmer cooperative case study}

We conducted this case study with a registered cocoa farmers' cooperative in Ghana. For the purposes of institutional anonymity, we refer to this organization as Farmer Co-op. The organization was formed in the early 1990s to serve the following needs of interested farmers: (1) to augment cocoa farmers' bargaining power; (2) to help manage cocoa production risks collectively; (3) to assist farmers to obtain subsidized cocoa inputs at a far lesser price than they could obtain on an individual basis; and (4) to ensure the long-term sustainability of Ghanaian cocoa production by encouraging resource-conserving agricultural practices. With an initial membership of approximately 3000 farmers, Farmer Co-op currently has almost 65,000 farmers in 1300 Ghanaian communities. It is one of the largest fair-tradecertified cocoa cooperatives in West Africa. It operates in all 5 cocoa-producing regions in Ghana, namely, Ashanti, Brong Ahafo, and Central, Eastern, and Western Regions.

As part of its sustainability goals, Farmer Co-op partnered with a European organization (hereafter EURORG) in 2011 to support cocoa agroforestry in Ghana. Under this partnership, EURORG agreed to provide full funding, while Farmer Co-op agreed to encourage its cocoa farmers to cultivate multipurpose trees on both cocoa farms and degraded lands. Three interrelated factors influenced this partnership agreement: first, to draw on the wellknown benefits of agroforestry (Asare et al. 2014, Vaast and Somarriba 2014) to ensure sustainable cocoa production in an era of increasing climatic change; second, to increase farmer incomes from diversified sources; and third, to avoid reliance on synthetic farm inputs while still maintaining the quality and quantity of cocoa production for the fair-trade market. The partnership commenced in 2011, with the cultivation of 50,000 trees in 13 cocoa-growing communities. In the following year (2012), a total of 100,000 tree seedlings were distributed and planted by farmers in 18 additional communities. Owing to increasing farmer interest in the cocoa agroforestry project, Farmer Co-op and EURORG in 2014 further added 10,000 trees in 4 cocoa-growing communities.

Once enrolled in the project, a farmer receives free seedlings and technical assistance on how to plant and manage the new trees. EURORG pays for the nursery and supply of seedlings, while cooperative farmers provide labor in the form of site preparation, pegging, tree planting, tending, and fire protection. Project communities were selected based on total farmer population and willingness to integrate trees into cocoa and subsistence farms. Farmers are required to choose from three agroforestry models. Model one (boundary planting) involves trees planted around the periphery of a cocoa parcel(Fig. 1A). Model two (mixed) involves trees mixed with cocoa and other subsistence crops (Fig. 1B). Model three (pure stand) involves trees cultivated as a plantation without integrating any cocoa or subsistence crop (Fig. 1C). A farmer can adopt one or more of the existing agroforestry models on multiple plots, but not on the same plot.

\section{METHODS}

\section{Site selection}

Our fieldwork was conducted from February to April 2016. A multistage sampling procedure was used to select the study region, districts, communities, and farmers. First, we held a series of consultations with Farmer Co-op officials to establish where it has had the longest presence in terms of promoting cocoa agroforestry. From these consultations, the Ashanti Region was selected, as cocoa agroforestry has been promoted in this region since January 2011. The region is located in central Ghana within the moist semideciduous forest zone $\left(5^{\circ} 50^{\prime}\right.$ to $7^{\circ} 46^{\prime} \mathrm{N}$ and $0^{\circ} 15^{\prime}$ to $2^{\circ} 25^{\prime} \mathrm{W}$ ). The majority of inhabitants rely on agriculture and rain-fed cultivation of cocoa, maize, cassava, yams, cocoyams, plantain, and other crops, which is practiced by both men and women (Ghana Statistical Service 2013). 
Table 1. Profile of the study communities. Data sources: Ghana Statistical Service (2013), field notes (2016), District Medium Term Development Plans (2012-2016).

\begin{tabular}{|c|c|c|c|c|c|}
\hline & \multicolumn{5}{|c|}{ Community } \\
\hline & A & $\mathrm{B}$ & $\mathrm{C}$ & $\mathrm{D}$ & $\mathrm{E}$ \\
\hline Total population (2016) & 1357 & 740 & 2056 & 4321 & 2767 \\
\hline Number of households & 388 & 123 & 478 & 617 & 692 \\
\hline Ethnic composition & Mainly Akans (87\%) & Mainly Akans (81\%) & Mainly Akans (92\%) & Mainly Akans (90\%) & Mainly Akans $(77 \%)$ \\
\hline $\begin{array}{l}\text { Number of farmers } \\
\text { interviewed }\end{array}$ & 16 & 16 & 18 & 25 & 29 \\
\hline Gender & $\begin{array}{l}11 \text { men, } \\
5 \text { women }\end{array}$ & $\begin{array}{l}12 \text { men, } \\
4 \text { women }\end{array}$ & $\begin{array}{l}17 \text { men, } \\
1 \text { woman }\end{array}$ & $\begin{array}{l}18 \text { men, } \\
7 \text { women }\end{array}$ & $\begin{array}{l}23 \text { men, } \\
6 \text { women }\end{array}$ \\
\hline Average land size (ha) & 14.4 & 17.3 & 25 & 15 & 16.1 \\
\hline Percent of migrants & 19 & 6 & 6 & 12 & 45 \\
\hline
\end{tabular}

Fig. 1. (A) Agroforestry model 1 with trees (Terminalia superba) along the periphery. (B) Agroforestry model 2 with trees ( $T$. superba) mixed with cocoa and other subsistence crops. (C) Agroforestry model 3 with a pure stand of T. superba. Source: Photos taken by authors.
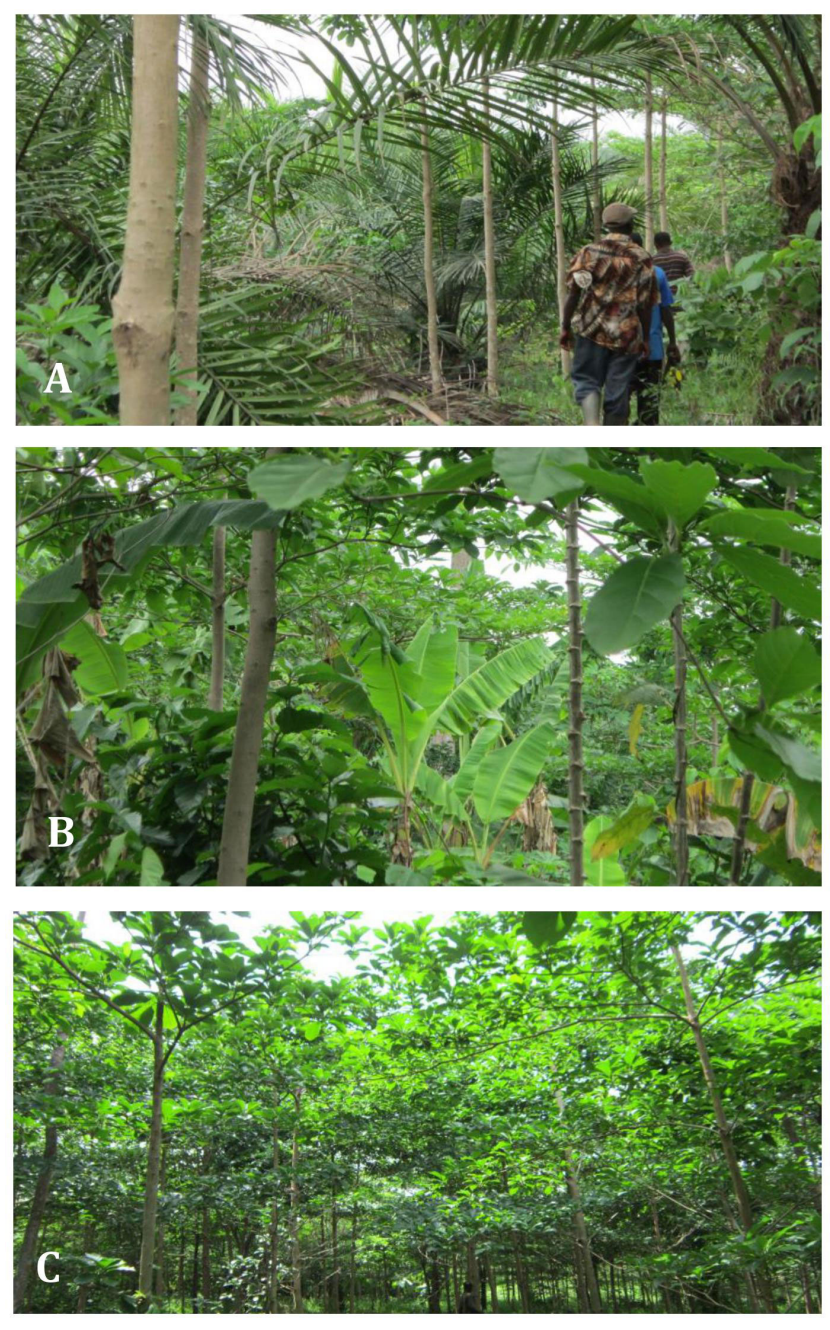

We then used purposeful sampling to select communities that met the following 2 requirements: (1) communities that took part in the very first wave of tree planting in 2011 and (2) communities with at least 15 farmers engaged in the cocoa agroforestry project. We selected the previous 2 criteria because 5 years (from 2011 to 2016) is sufficient to measure community-level environmental outcomes, namely, differential storage of carbon in aboveground biomass from the agroforestry project (Vashum and Jayakumar 2012). Moreover, we preferred networks of a similar size for comparability.

Overall, there are 30 administrative districts in the selected region. We conducted fieldwork in 4 districts and 5 relatively smaller communities, ranging in population from 740 to 4321 people. The communities are in geographically disparate locations. On average, they are about $29 \mathrm{~km}$ apart and have no apparent crossover in social relations. They are very similar in terms of ethnic composition and agricultural practices, but they differ in other aspects such as the presence and duration of interventions by nongovernmental organizations (NGOs). The main characteristics of the 5 communities are contrasted in Table 1, in terms of size, number of households, ethnic composition, land ownership, and the number of farmers interviewed. All of the information in Table 1 was collected from meetings with village men and women and corroborated through census reports from Ghana Statistical Service. We gained access to the communities and their cocoa agroforestry farmers through several consultations with Farmer Co-op.

Community A has 1357 inhabitants, and it is the fourth largest site among the 5 study communities. It is located about $35 \mathrm{~km}$ from the nearest town, and not less than $21 \mathrm{~km}$ from any of the other study communities. Since 2006, the community has seen an increasing presence of NGOs, with projects including agroforestry, climate change adaptation, soil conservation, and the introduction of new maize varieties. Community $\mathrm{B}$ is the poorest among the 5 sites in terms of infrastructural development. There are 740 inhabitants in the community, all of whom are engaged in cocoa cultivation and subsistence food production. No NGO activities are found at this site, and the community is not accessible by motorized vehicle during the rainy season. Because of its remote location and poor road conditions, farmers in the community struggle to sell their agricultural produce. The nearest town is located $43 \mathrm{~km}$ away. Community $\mathrm{C}$ has a population of 2056 and is located not less than $37 \mathrm{~km}$ from the 
remaining study sites. It has had NGO presence since 2001, with projects including soil and water conservation, cocoa agroforestry, and the formation of farmer seed-sharing groups. Compared with the other study sites, Community $\mathrm{C}$ is relatively developed in terms of community infrastructure such as roads, schools, and health facilities. Agriculture was the only livelihood strategy in the community until the late 1990s, when small-scale gold mining became popular. Community D is the largest among the study sites in terms of population (4321 people). Among the 5 sites, it is also the community with the longest presence of NGO activities, with projects including cocoa agroforestry, cane rat (Thryonomys swinderianus) rearing, and soil and water conservation. Moreover, it is one of the communities with the longest history of cocoa production in Ghana's Ashanti Region. It is located $21 \mathrm{~km}$ from the nearest town and an average of approximately $29 \mathrm{~km}$ from the other study sites. Community E is an isolated site, cut off from all nearby settlements. It has a population of 2767 inhabitants and is located approximately 28 $\mathrm{km}$ from the other 4 sites. Cocoa farming and subsistence crop cultivation constitute the main livelihood activities. Unlike the other 4 sites, mobile phone connectivity is very poor in Community E, making intracommunity information exchange difficult.

\section{Demographic and network data collection}

In each selected community, we obtained a complete list of registered farmers under the Farmer Co-op project and administered a survey to all farmers participating in the cocoa agroforestry project. Although the agroforestry parcels belong to individual households, or a group of families, the target survey population was defined as the household or family member under whose name the agroforestry parcel is officially registered, the one who actually receives initial training for the agroforestry project and also attends regular monthly and agricultural extension meetings organized by Farmer Co-op. This sampling protocol achieves a "community" network in each village insofar as we interviewed everyone listed in the cooperative. In essence, our "community" networks and "community" outcomes are based on the cooperative community, not the village as a whole.

The survey instrument consisted of 41 questions grouped under 3 sections. Section 1 contained background information about the farmer, including age, gender, land size, education, marital status, number of years as a member of Farmer Co-op, agricultural production practices, and total annual income. Section 2 contained questions about the social and physical attributes of the land being used for cocoa agroforestry, including land tenure, types of crops, types of tree species on the land, the number of tree seedlings received, and the type of agroforestry model adopted. Section 3 contained questions about farmer-tofarmer information-sharing networks. The respondents were provided a list of all Farmer Co-op project participants in their communities and then asked to identify from the list any person from whom they receive information. The exact English translation of the network prompt was as follows: "Among this list of farmers involved in the cocoa agroforestry, which of them do you contact to seek advice, learn from, or acquire information, regarding cocoa farming and agroforestry?"We then followed this question with a series of questions about the nature, frequency, and mode of contact for information sharing. Reported elicited ties were present at the time when the biomass was measured.
After a farmer had identified all possible contacts on the list, he or she was asked to name any other person not included on the list from whom information was sought on farming or agroforestry. Actor responses on information sharing were coded as binary variables (where " 1 " indicates the presence of a tie and " 0 " indicates the absence of a tie) and entered into an $n \times n$ adjacency matrix, where $n$ stands for total number of actors.

All surveys were completed by the authors and a trained research assistant. The survey was administered face-to-face and conducted in Twi, the local language in the study communities. A total of 104 farmers fully completed the surveys, with the following sample sizes across communities: Community $\mathrm{A}(n=$ 16), Community B $(n=16)$, Community $\mathrm{C}(n=18)$, Community $\mathrm{D}(n=25)$, and Community $\mathrm{E}(n=29)$. The response rate was $96 \%$ for Community E and 100\% for the remaining communities. This research received ethics approval from the Social Sciences, Humanities and Education Research Ethics Board, University of Toronto, for research involving human participants. Informed consent was secured in advance of every interview.

\section{Environmental data collection}

We used calculated aboveground biomass and carbon storage derived from the adoption of the agroforestry project as the individual- and community-level environmental outcome. To do this, aboveground biomass for the Farmer Co-op/EURORG planted trees within a randomly assigned $10 \mathrm{~m} \times 10 \mathrm{~m}$ plot in these agroforestry systems was calculated from measured diameter at breast height and tree height using a generalized tree biomass regression for tropical moist stands (Chave et al. 2014):

$$
y=0.0673 \times\left(0.43 \times D B H^{2} \times H^{0.976}\right)
$$

where $y$ is the aboveground biomass $(\mathrm{kg}), 0.43$ is a generalized wood density, DBH is diameter at breast height $(\mathrm{cm})$, and $H$ is the tree height $(\mathrm{m})$. Biomass is reported on a $10 \times 10 \mathrm{~m}$ plot basis $\left(100 \mathrm{~m}^{2}\right)$ as well as extrapolated to a farm basis based on reported farm size and verified with field measurements. Biomass values per farm were summed for all individuals in a community to estimate total biomass accumulated from the adoption of agroforestry per community. Aboveground biomass associated with the agroforestry project on a plot, farm, and community scale and the agroforestry model selection were analyzed for statistical differences among communities.

\section{Data analysis}

\section{Standard network data analysis}

Network data was analyzed for a number of network metrics. Indegree is the number of incoming links (or using the terminology of graph theory, "edges") to a network node (or a "vertex"). Outdegree is the number of outgoing links. Graph density indicates the proportion of existing links to all pairs of nodes in a network, i.e., the actual number of links divided by the potential theoretical maximum number of links that could exist on a given set of nodes. Transitivity indicates the proportion of pairs of directly connected network nodes among pairs of nodes that have a network partner in common. High transitivity signifies a high proportion of closed triangles in networks, in which friends of friends are likely to be friends. Although 2-star is an elementary part of a network (or network "motif"), in which two nodes are 
Fig. 2. Structural and actor attribute parameters included in models.

\begin{tabular}{|c|c|c|c|}
\hline \multicolumn{2}{|l|}{ Parameters } & \multirow{2}{*}{$\begin{array}{l}\text { Description and Interpretation } \\
\text { The number of social ties in the network or } \\
\text { tendency for tie formation. }\end{array}$} & \multirow[t]{2}{*}{ Visualization } \\
\hline \multirow{5}{*}{ Structural } & Edge & & \\
\hline & 2-Star & $\begin{array}{l}\text { Popularity: indicative of the presence of an } \\
\text { actor who is highly sought for agricultural } \\
\text { information/advice. }\end{array}$ & \\
\hline & Triangle $\left(\mathrm{T}_{1}\right)$ & $\begin{array}{l}\text { A tendency towards reciprocity, meaning } \\
\text { there are a number of ties that are mutual } \\
\text { among actors. }\end{array}$ & \\
\hline & 2-Triangle $\left(\mathrm{T}_{2}\right)$ & Tendency towards network closure. & \\
\hline & Alt-Star (AS) & $\begin{array}{l}\text { Popularity spread: tendency towards the } \\
\text { formation of hubs. AS models the network } \\
\text { distribution more generally, with a positive } \\
\text { effect indicating degree centralization. }\end{array}$ & \\
\hline \multirow[t]{3}{*}{$\begin{array}{l}\text { Actor } \\
\text { attribute }\end{array}$} & Sum & $\begin{array}{l}\text { Link is likely between two actors if at least } \\
\text { one of the two, but ideally both, score high } \\
\text { on a given attribute (in this case } \\
\text { aboveground biomass). }\end{array}$ & \\
\hline & Difference & $\begin{array}{l}\text { Link is likely if there is a high difference in a } \\
\text { given attribute between two actors } \\
\text { (heterophily). }\end{array}$ & \\
\hline & Product & $\begin{array}{l}\text { Link is likely between two actors if both } \\
\text { score high on a given attribute (in this case } \\
\text { aboveground biomass). It is about the } \\
\text { interaction of the attributes between } 2 \text { actors. }\end{array}$ & \\
\hline
\end{tabular}

Source: Adapted from Wang et al. (2009, pp. 32-33).

connected to a common third node, in triangles, all three nodes are directly connected to one another. "2-Triangles" are two adjacent triangles connected to one another by a common edge. Isolates are nodes (or vertices) with no links (or edges). Given our research design, we compared these network metrics to environmental outcomes (biomass per farm and total biomass at the community level). All network analysis was conducted in R v. 3.0.2 ( $\mathrm{R}$ Foundation for Statistical Computing, Vienna, Austria) and visualization in Netdraw (Borgatti 2002).

\section{Exponential random graph models}

We fitted ERGMs to assess the similarities and differences among the five networks. ERGMs were estimated using the software PNET, with the Nondirected Network option (Wang et al. 2009). The reason the networks were modeled as undirected was because converged estimates could not be obtained for directed data. ERGMs, although a powerful technique that enables researchers to conduct analyses that are impossible with traditional methods, have known issues of model degeneracy where parameter values produce bimodal or multimodal distributions that do not match the observed network. Maximum likelihood estimates are unreliable under such ERGM specifications. Thus, in the present
ERGM models, two actors are considered connected if either of them (or both of them) mentioned the other as a source of information. Therefore, the ERGM results do not distinguish popular advisers from active information seekers. To test whether all of the networks could be represented jointly by the same network mechanisms, we composed a model with all communities in the same model and tested the same, as well as alternative, specifications. None of the models converged suggesting that the processes operating in the respective communities are too diverse to be captured by the same model. The communities are far apart, and the respondents reported no interlinkages. This fact was represented in the joint model by "structural zero," that is, designated pairs of nodes between which the model does not create any links during simulations. For completeness, we also tested joint models without structural zeros, but these did not converge either, which was expected.

We applied a common model specification (using the same set of parameters for multiple models) estimated separately for each of the five communities. In the models, we included several structural parameters (Fig. 2), including star- and triad-based effects, to represent the network structure, basing our selection on previous 
literature (e.g., Lusher et al. 2012). High clustering and skewed degree distribution are common properties of many real-world social networks (Kadushin 2012). It has been long known that real social networks tend to be significantly more clustered than what would be predicted by a random model (Davis 1970). This high network transitivity and skewed degree distribution need to be controlled for in ERGM by the inclusion of star- and triadbased effects. Stars represent high degree nodes, and the prevalence of closed triangles quantifies the degree of clustering in a network. The exact specification of these parameters for each network is decided empirically by goodness-of-fit (GOF) tests.

We started with the most fundamental network parameters (e.g., edge, 2-star, triangle, and isolates) and then tested the response of the model when higher order parameters were added, which is the recommended approach (Wang et al. 2009). For example, we would obtain misleading results if we included an effect representing two triangles attached to each other $\left(\mathrm{T}_{2}\right)$ without "controlling for" the overall number of triangles by a single triangle parameter $\left(T_{1}\right)$ and, even more critically, the overall number of edges in the network. This is similar to traditional regression analysis for which it is typically recommended to include separate variables in addition to interactions in which these variables are used.

Guided by substantial theoretical considerations and GOF statistics, the first focus of the model-fitting process was on the endogenous network effects. The specification was modified if the model degenerated, or if the model did not converge for all five networks. A model is considered better if it provides adequate fit to more auxiliary statistics that are not part of the model. When including any new structural effects did not seem to improve the model fit anymore, the fitting effort shifted to node characteristics.

We tested a number of actor attribute parameters, separately and in combinations, including demographic variables indicating gender, income, land size, the migration status of the respondent, and environmental outcomes, specifically biomass. Again, actor attribute parameters were excluded and new ones included if the model degenerated, did not converge, or their inclusion worsened the model fit. We continued with this process to refine the models until we reached a final model specification that led to convergence and acceptable fit for all five networks. The node characteristics were considered in effects titled (1) "sum," (2) "difference," and (3) "product." These three effects as a set examine the role in information exchange of (1) at least one of the farmers in a pair maintaining large levels of biomass, (2) the difference between two farmers' levels of biomass, and (3) both farmers having large biomass. The sum effect examines the possibility of whether a link is more likely between two actors who have high amounts of biomass on their plot in sum. The sum can be high even if one of the actors has almost no biomass on the farm, in the case where the biomass on the other actor's farm is high. This characteristic distinguishes the sum effect from the product effect: If one of the farmers keeps very little biomass on the plot, the product will be small even if the other farmer maintains high levels of biomass.

We do not present the incomplete specifications that produced simulated networks that do not match the observed reality because their parameters are meaningless. The best-fitting model for one community might not be the best-fitting model for another community. Our goal was to obtain acceptable fit for all communities with the same specification to obtain comparable results. This proved possible with only a single exception of 2triangle $\left(\mathrm{T}_{2}\right)$, which was not included in the case of Community $\mathrm{C}$, as the ERGM did not converge if this effect was included. The only actor-level variable that contributed to the model fit was the biophysical measure of biomass. All other actor-level variables had to be excluded.

At the end of the estimation process, our model converged for every parameter based on the $t$ statistics for convergence $(t<0.1)$. Our model also met the requirements for GOF suggested by Koskinen and Snijders (2012), as well as Robins and Lusher (2012). GOF captures the extent to which observed data match the values expected in theory, and this is calculated by using a standardized difference with mean $=0$ and standard deviation $=$ 1 (Koskinen and Snijders 2012). Its threshold is ideally below 0.1 for variables included in the model and below 2 for nonincluded variables, although occasional higher values are also acceptable (Robins and Lusher 2012). In our case, GOF was below 2 for all variables, and the Mahalanobis distances were small, thus suggesting reliable estimates.

\section{RESULTS}

\section{Actor and network attributes}

The study sample included more men $(75 \%)$ than women $(25 \%)$. The respondents ranged in age from 28 to 90 years old, with an average of 56 years. Average household size was 10 members, a figure larger than the average household size in the Ashanti Region (4.2 members per household; Ghana Statistical Service 2013). On average, the respondents were cultivating farmlands of approximately 17.1 ha, with a range of 2 to 200 ha (only 1 respondent had a rather large land holding of $200 \mathrm{ha}$ ) and earning an annual income of US\$3199. Table 1 summarizes this demographic information and provides additional information about the sample population and the study communities.

Network descriptive statistics across the five communities are presented in Table 2. Although the 5 communities exhibited relatively similar community network characteristics, Community $\mathrm{D}$ had the highest number of connections per actor in a community (3.88), 58\% higher than the lowest number of connections per actor in a community (Community B). Simultaneously, Community D shows the highest transitivity

Table 2. Network descriptives of the five communities. SD, standard deviation.

\begin{tabular}{lccccc}
\hline \hline & \multicolumn{5}{c}{ Community } \\
\cline { 2 - 6 } & $\mathrm{A}$ & $\mathrm{B}$ & $\mathrm{C}$ & $\mathrm{D}$ & $\mathrm{E}$ \\
\hline Vertices & 16 & 16 & 18 & 25 & 29 \\
Edges & 51 & 36 & 47 & 97 & 74 \\
Mean degree & 3.18 & 2.25 & 2.61 & 3.88 & 2.55 \\
Indegree SD & 2.71 & 1.13 & 3.87 & 1.20 & 2.69 \\
Outdegree SD & 1.33 & 1.34 & 1.57 & 3.37 & 2.01 \\
Indegree-outdegree correlation & 0.07 & 0.25 & 0.66 & -0.22 & 0.26 \\
Graph density & 0.21 & 0.15 & 0.15 & 0.16 & 0.09 \\
Transitivity (undirected) & 0.41 & 0.45 & 0.42 & 0.56 & 0.42 \\
\hline
\end{tabular}


Fig. 3. Information-sharing networks in the five communities (A-E). Node sizes correspond to the biomass per hectare on the farmer's plot. Gray nodes represent community members who could not be interviewed and whose biomass data are not available. Arrows point from the information recipient to the information provider.

A

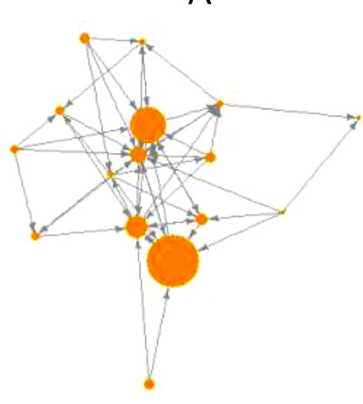

B

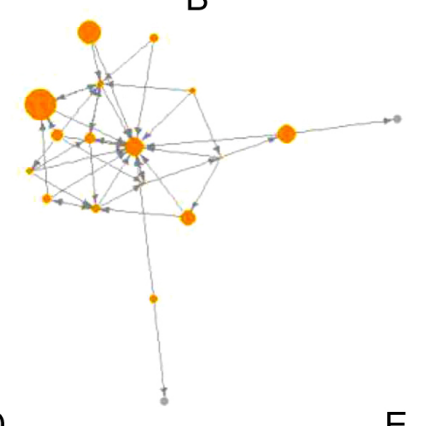

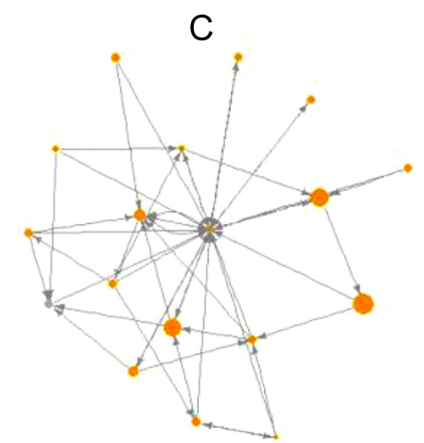

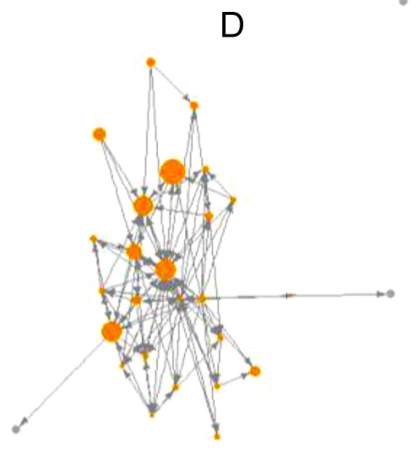

$E$

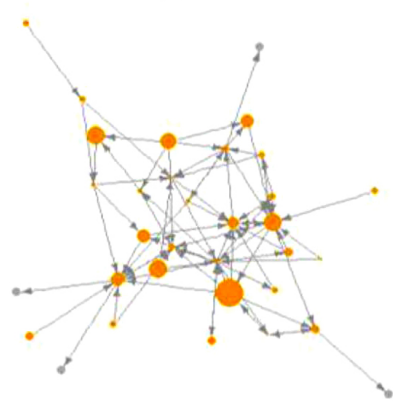

mean (0.56), indicating that the probability of a link increased to $56 \%$ for people who have a common partner because of the clustering tendencies in the network. Community A exhibited the highest network density $(0.21)$, which means that $21 \%$ of pairs of individuals in the village are connected by an information-sharing link. All community networks are visualized in Figure 3.

Farm- and community-level environmental outcomes

The mean aboveground biomass in trees planted under the agroforestry project ranged among the 5 communities from 98.1 to $162.1 \mathrm{~kg}$ of biomass per $100 \mathrm{~m}^{2}$ plot (Table 3 ). When these biomass values calculated from allometric equations were scaled to the whole farm, mean values ranged from 18.0 to 65.7 megagrams $(\mathrm{Mg}) /$ farm indicating a near threefold range in aboveground biomass and, therefore, variable carbon storage associated with the agroforestry projects among the communities (9.8 to $16.2 \mathrm{Mg} \mathrm{C/farm).} \mathrm{The} \mathrm{data} \mathrm{in} \mathrm{Table} 3$ show mean aboveground biomass per agroforestry model among the communities. Although the pure stand model was not popular (only $13 \%$ of farmers adopted this model), it contained the highest average biomass at the hectare scale $(222.3 \mathrm{Mg} / \mathrm{ha})$ because of higher densities of planting, compared with the trees mixed with cocoa and other subsistence crops $(82.27 \mathrm{Mg} / \mathrm{ha})$ and then trees along periphery of a parcel $(82.18 \mathrm{Mg} / \mathrm{ha}$; see Table 3$)$.

\section{Observed networks and environmental outcomes}

Table 4 describes the relations between main network and environmental variables. Indegree and transitivity are the most strongly correlated pair of variables in the data set, and their correlation is negative $(r=-0.421 ; P<0.001)$. This indicates that
Table 3. Mean ( \pm standard deviation [SD]) aboveground biomass in planted trees. Values at the plot scale $\left(\mathrm{kg} / 100 \mathrm{~m}^{2}\right)$, the total farm scale $(\mathrm{Mg} / \mathrm{farm})$, and the community scale $(\mathrm{Mg} /$ community) are shown. Also shown is mean ( $\pm \mathrm{SD})$ aboveground biomass in planted trees in each agroforestry model type ( $\mathrm{Mg} /$ model type; $n$ = individuals per model type across all communities).

\begin{tabular}{cccc}
\hline \hline Community & $\begin{array}{c}\text { Mean Biomass } \\
\text { per Plot }\end{array}$ & $\begin{array}{c}\text { Mean Biomass } \\
\text { per Farm }\end{array}$ & $\begin{array}{c}\text { Total Biomass per } \\
\text { Community }\end{array}$ \\
\hline A & $156.8 \pm 151.7$ & 65.7 & 1051.3 \\
B & $126.9 \pm 83.2$ & 38.4 & 614.3 \\
C & $104.4 \pm 48.8$ & 18.0 & 324.3 \\
D & $99.2 \pm 65.9$ & 32.6 & 803.7 \\
E & $98.1 \pm 63.6$ & 34.7 & 920.4 \\
& \multicolumn{4}{c}{ Mean biomass per model type } \\
& Model 1 $(n=28)$ & Model 2 $(n=82)$ & Model 3 $(n=16)$ \\
& $82.2 \pm 56.4$ & $82.2 \pm 59.2$ & $222.2 \pm 128.1$ \\
\hline
\end{tabular}

popular farmers have less dense individual networks. Similarly, farmers who report access to more sources of information within the community have sparser individual networks $(r=-0.215 ; P=$ $0.031)$. We found a significant correlation between biomass and indegree $(r=0.217 ; P=0.026)$. Farmers who are considered useful sources of agricultural knowledge in the community tend to have more biomass on their agroforestry plots. However, biomass accumulation is unrelated to outdegree, i.e., the number of peers the respondents reported as their source of information. 
Table 4. Pearson correlation coefficients $(r)$ and respective $P$ values are presented for each pair of variables (biomass, indegree, outdegree, and transitivity) below the diagonal. Ordinary least squares regression slopes are presented above the diagonal. The betas represent the change in the variable indicated in the first column of the table that corresponds to a unit change of the respective variable indicated in the top row of the table. The $P$ values associated with the regression coefficients are identical to the correlation $P$ values below the diagonal.

\begin{tabular}{lcccc}
\hline \hline & Biomass & Indegree & Outdegree & Transitivity \\
\hline Biomass & & $B=5.189$ & $B=-1.079$ & $B=-52.69$ \\
Indegree & $r=0.217$ & & $B=0.257$ & $B=-5.547$ \\
& $P=0.027$ & & & \\
Outdegree & $r=-0.032$ & $r=0.180$ & & $B=-1.988$ \\
& $P=0.750$ & $P=0.067$ & & \\
Transitivity & $r=-0.167$ & $r=-0.421$ & $r=-0.215$ & \\
& $P=0.095$ & $P=0.000$ & $P=0.031$ & \\
\hline
\end{tabular}

\section{Exponential random graph model estimations}

In Table 5, results of the model estimations are presented. The results are arranged in two horizontal sections: first, structural network parameters across communities; and second, environmental outcomes (aboveground biomass). In each case, only the parameter estimates and the standard errors are given. The estimate of each parameter is computed "while controlling" for other parameters in the model, and therefore, the interpretation of each parameter should be conducted while considering other effects in the model. For example, the edge parameter in the model is a control for link density, and it is negatively significant in two communities ( $\mathrm{C}$ and $\mathrm{E})$. This means that a tendency for establishing links between individuals is not prevalent in these community without the presence of other effects, e.g., one of the nodes is a high-degree node, and thus an addition of the link would increase the number of positively significant 2-star motifs in the model.

Overall, the ERGM results show positive and significant estimates of the 2-star parameter (Table 6), which suggested a clustering of advice-seeking ties on the most popular advisers. The 2-star effect is closely related to the Alt-Star (AS) effect, which is mostly nonsignificant in the model. The presence of both effects was necessary to fit the model well. Finally, the aboveground biomass data was included in the model to improve convergence or model fit. Biomass data is correlated with indegree $(r=0.217 ; P=0.026)$ in our observed network data, which means that more popular advisers are farmers with more biomass on their plots.

\section{DISCUSSION AND CONCLUSIONS}

Our main objective was to identify information network structures within rural cooperatives and what these structures mean for resource-conserving agriculture. We pursued this objective by using comprehensive data on information-sharing networks among farmers in a rural cooperative in Ghana. The data were analyzed using standard social network analysis, combined with ERGM estimation and GOF tests (Robins and Lusher 2012). We further put greater analytical weight on environmental outcomes, namely, biomass stocks and sequestered carbon associated with the adoption of agroforestry practices, to contribute to understanding whether and how biophysical characteristics are linked to microlevel social relations or network structures. Subsequently, we discuss our findings under three broad themes.

\section{Resource-conserving agriculture, environmental outcomes, and observed networks}

Variation in the selection of agroforestry models had a substantial impact on the amount of biomass accumulated. The majority of farmers $(87 \%)$ adopted agroforestry models that incorporated trees into current cropping systems; this choice resulted in higher but variable amounts of biomass above that which would have been stored without the agroforestry program. This increase in biomass, and subsequently carbon, is positively correlated to the number of connections of an individual farmer, indicating that farmers who were more popular advisers (measured by the number of their incoming ties) also tended to have slightly higher biomass stocks in the adopted agroforestry systems. Our ERGM analysis supports this finding. The positive and significant ERGM result for an individual's popularity (the 2-star effect) across all but one of the communities suggests that networks are structured around knowledgeable actors. This finding on the role of popularity, advice seeking, and environmental outcomes found in both standard network analysis and ERGM analysis is further refined for Community $\mathrm{C}$, where we show a positive and significant sum estimate, suggesting that networks are formed around not just knowledgeable actors but knowledgeable actors with high levels of aboveground biomass.

Overall, these findings are in line with previous findings on the structure of individual networks and adoption of proenvironmental practices, insofar as those who express good farming practices are highly sought after (Isaac et al. 2007, Matouš et al. 2013, Isaac et al. 2014, Matous and Todo 2018). When making decisions regarding from whom to seek advice or with whom to share inputs, farmers would often reach out to peers who have demonstrated clear signs of successful farming practices (Wood et al. 2014). These actors seem to play a more active, communicative role in their networks. However, the important individual network structural feature, the triangle, was weakly negatively related to biomass stocks of an individual plot $(r=-0.167 ; P=0.095)$. Clustered networks may enable information sharing and diffusion at the collective level (Matous and Todo 2015, Barnes et al. 2016), but it is not necessarily the most clustered individuals, i.e., individuals with high transitivity scores who have a high proportion of communication partners who also talk to one another, that adopt agroforestry practices with high biomass accumulation.

\section{Network fit and the role of environmental outcomes}

Although there is a large body of empirical work on the structural characteristics of social networks in natural resource management (for a review, see Bodin and Crona 2009), only a relatively smaller number of studies have used ERGMs to investigate multiple networks. Currently, the strongest research focused in this area seems to be on networks at different levels (Bellotti et al. 2016, Brailly et al. 2016, Brennecke and Rank 2016, Hollway and Koskinen 2016, Wang et al. 2016, Zappa and Lomi 2016). Not many studies have examined multiple comparable networks within the same level to assess the relation of their 
Table 5. Results from the exponential random graph model (ERGM) parameter estimation. Goodness of fit: The $t$ statistics of all parameters included in the model were below the threshold value of 2, thus suggesting a good model fit (Koskinen and Snijders 2012, Robins and Lusher 2012). ${ }^{*} P<0.05$. SE, standard error.

\begin{tabular}{|c|c|c|c|c|c|c|c|c|c|c|}
\hline \multirow{3}{*}{ Multiple Network Effects } & \multicolumn{10}{|c|}{ Community } \\
\hline & \multicolumn{2}{|c|}{$\mathrm{A}$} & \multicolumn{2}{|c|}{$\mathrm{B}$} & \multicolumn{2}{|c|}{$\mathrm{C}$} & \multicolumn{2}{|c|}{$\mathrm{D}$} & \multicolumn{2}{|c|}{$\mathrm{E}$} \\
\hline & Estimate & SE & Estimate & SE & Estimate & SE & Estimate & SE & Estimate & $\mathrm{SE}$ \\
\hline \multicolumn{11}{|l|}{ Structural } \\
\hline Edge & -1.28 & 1.48 & 1.77 & 2.93 & $-4.31 *$ & 2.41 & 2.35 & 2.86 & $-2.79 *$ & 0.96 \\
\hline 2-Star & $0.31 *$ & 0.13 & -0.20 & 0.83 & $0.42 *$ & 0.07 & $0.25^{*}$ & 0.05 & $0.20^{*}$ & 0.04 \\
\hline Triangle $\left(\mathrm{T}_{1}\right)$ & 2.15 & 1.33 & 0.60 & 0.89 & 0.49 & 1.49 & 0.21 & 0.59 & 1.46 & 0.98 \\
\hline 2-Triangle $\left(\mathrm{T}_{2}\right)$ & -0.64 & 0.52 & $L^{\dagger}$ & & $-22.69 *$ & 3.15 & -0.09 & 0.15 & -1.27 & 0.91 \\
\hline Alt-Star (AS) & -0.76 & 0.59 & -0.66 & 2.00 & -0.31 & 0.55 & -1.87 & $0.82 *$ & -0.06 & 0.30 \\
\hline \multicolumn{11}{|l|}{ Aboveground biomass } \\
\hline $\operatorname{Sum}\left(\times 10^{3}\right)$ & -3.60 & 7.34 & 7.34 & 9.33 & $6.06^{*}$ & 0.02 & 6.95 & 7.92 & 9.15 & 5.67 \\
\hline Difference $\left(\times 10^{3}\right)$ & -1.30 & 4.83 & 1.26 & 6.80 & -8.58 & 9.26 & -5.00 & 5.27 & 5.30 & 3.73 \\
\hline Product $\left(\times 10^{3}\right)$ & 0.03 & 0.05 & 0.06 & 0.06 & -0.16 & 0.21 & -0.05 & 0.07 & 0.08 & 0.05 \\
\hline
\end{tabular}

${ }^{\dagger}$ The ERGM did not converge if this configuration was included. Thus, it was excluded from the model.

Table 6. Exponential random graph model (ERGM) positive and negative significant estimates.

\begin{tabular}{lcc}
\hline \hline $\begin{array}{l}\text { Multiple Network } \\
\text { Effects }\end{array}$ & $\begin{array}{c}\text { Number of } \\
\text { Communities Showing } \\
\text { Positively Significant } \\
\text { Estimates }\end{array}$ & $\begin{array}{c}\text { Number of } \\
\text { Communities Showing } \\
\text { Negatively Significant } \\
\text { Estimates }\end{array}$ \\
\hline Structural & 0 & 2 \\
Edge & 4 & 0 \\
2-Star & 0 & 0 \\
Triangle $\left(\mathrm{T}_{1}\right)$ & 0 & 1 \\
2-Triangle $\left(\mathrm{T}_{2}\right)$ & 0 & 1 \\
Alt-Star $(\mathrm{AS})$ & 1 & 0 \\
Aboveground biomass & 0 & 0 \\
Sum $\left(\times 10^{3}\right)$ & 0 & 0 \\
Difference $\left(\times 10^{3}\right)$ & & \\
Product $\left(\times 10^{3}\right)$ & & \\
\hline
\end{tabular}

structural characteristics with network-level collective outcomes (Matous 2015, Bodin et al. 2017), and only a few recent studies have analyzed multiple comparable network communication structures in environmental management using ERGMs (Bodin et al. 2017, Levy and Lubell 2018, Matous and Wang 2019). Similarly, we found that among the five communities, there was no clear pattern in relationships, yet we did not find the opposite results for any two communities either. Furthermore, in an attempt to quantify general tendencies, we attempted to fit the entire data set of all communities into a single model (similar to Matous and Wang 2019). However, we did not succeed in reliably fitting these five communities in the same model. Apparently, distinct network mechanisms are at work across these communities, a clear indication that we need to be cautious when generalizing from network studies of single communities. We see some clear associations between number of links, clustering, and environmental outcomes at the node level, as well as some similar structural mechanisms such as the 2-star result across all but one of the communities. However, among the five networks, there is no indication that larger, denser, or more clustered communities would have different levels of biomass than communities that are smaller or sparser, or networks that have more evenly distributed relationships among the actors. Although the number of networks in our study does not allow us to provide an authoritative answer to this issue, our results suggest that relationships between community-level outcomes and collective network structure may be different from the relationship between individual-level outcomes and personal network structure, thus supporting previous findings of the first studies on this topic.

\section{Implications for exponential random graph model research, agricultural policy, and farmer development}

As several scholars have noted, building local capacity to adapt to environmental change would depend very much on social capital, including the close social bonds that facilitate cooperative action and the social bridging and linking via which ideas and resources are accessed (e.g., Pretty 2003, Armitage et al. 2009). The resulting insights from our study could therefore be used proactively to think about scaling pathways with respect to resource-conserving farming practices under global environmental change. A common deterrent to the adoption of these farming practices is the large number of "soft" inputs required, especially exposure to new ideas and the skill of experimentation (Silici 2014). Taken together, our findings illustrate how the existing structural characteristics of farmer networks, or relational ties, could enhance or hinder the information sharing and knowledge transfer often needed to support the scaling of resourceconserving agricultural practices. Although we offer these findings, our study is restricted to one moment in time, a general limitation to cross-sectional studies. Future research should also assess across multiple points in time to truly capture adoption practices and impacts on resource-conservation agriculture and land use practices in general (see Isaac and Matous 2017).

Our findings contribute to the existing literature in two principal ways. First, because of resource-conserving agriculture's reliance on knowledge and management intensiveness, farmers need to build social relations that easily foster knowledge transfer and information exchange. Drawing on comprehensive primary data, we find evidence showing that farmers who demonstrate clear signs of successful farming practices also tend to be popular advisers within a cooperative to their peers at the individual 
network level. Based on this finding, we conclude that using these "popular advisers" to spearhead knowledge exchange among farmers could help to foster social learning and experimentation within cooperatives that is all too often needed in conservation agricultural practices. However, it should be noted that popular advisers might also experience leadership fatigue as well as express resistance to external influences given their strong community connections (Matouš et al. 2013). However, because they have a higher likelihood of facilitating communication among members in their network, and perhaps the whole community, they could act as influential forces for encouraging the diffusion of innovative farming practices, given the right conditions (Valente 1996, Isaac et al. 2014). Indeed, they could spearhead knowledge exchange opportunities beyond what is typically available through the formal institutions of government. Further, using these presumably "skillful" local farmers to facilitate resourceconserving agricultural innovations could curb the top-down transfer of farming knowledge, a major criticism of agricultural extension delivery in most developing countries (Schut et al. 2014).

Second, beyond providing insights into how biophysical characteristics are linked to microlevel social relations or network structures, we contribute to the newly emerging field of ERGM research (e.g., Robins, Pattison, et al. 2007, Robins, Snijders, et al. 2007, Wang et al. 2013, Dickison et al. 2016, Wang et al. 2016). Using ERGM analysis provided the optics to analyze the significance of the observed network structures. Although ERGMs allow for a different level of focus, ERGMs have some limitations including convergence issues that allowed us to model only undirected ties in our study. Analysis for each community with ERGM suggests that commonly observed individual-level results might not scale to the collective level in a trivial manner because of endogenous network effects that we typically fail to capture at the individual scale. Although individual networks have been thoroughly explored, we need more studies with a larger number of networks to understand what kind of network structures are effective for whole collectives, such as the cooperatives in our study, and to measure environmental impacts at a large scale. To our knowledge, this is one of the first studies that focuses on using ERGMs not only to analyze whether different types of actors are associated with different types of network structures, but also to assess whether there is some universality in the structural and attribute elements required to model across multiple networks.

We also contribute a focus on environmental outcomes within ERGM analysis, specifically resource-conserving agricultural practices. In our ERGMs, we overlaid several structural parameters with an environmental variable, measured as aboveground biomass. Specifically, we show a relationship between this biophysical indicator and social structures within this cooperative. Farmers seek information from colleagues depending on their knowledge and practices, which is reflected in the overall biomass accumulation from the adoption of agroforestry practices on their plots. Not only was this environmental variable required for model convergence, but by paying attention to social and biophysical attributes simultaneously, our understanding of whether and how microlevel social relations are linked to community-level environmental outcomes is deepened.
Responses to this article can be read online at: http://www.ecologyandsociety.org/issues/responses. php/10623

\section{Acknowledgments:}

The authors sincerely thank Dr. Evans Dawoe and Dr. Luke Anglaaere for support during the initial stages of the fieldwork. Additional thanks are due to research assistant Mr. Kingsley Boadi whose contributions have been immeasurable in this work. We thank all study participants who took part in the survey and greatly appreciate local village elders who granted us access to the study communities. This article is based on fieldwork conducted with funding from the Canada Research Chairs program and a Social Sciences and Humanities Research Council of Canada Insight Development Grant to M. E. Isaac.

\section{LITERATURE CITED}

Altieri, M. A., C. I., Nicholls, A. Henao, and M. A. Lana. 2015. Agroecology and the design of climate change-resilient farming systems. Agronomy for Sustainable Development 35(3):869-890. http://dx.doi.org/10.1007/s13593-015-0285-2

Armitage, D. R., R. Plummer, F. Berkes, R. I. Arthur, A. T. Charles, I. J. Davidson-Hunt, A. P. Diduck, N. C. Doubleday, D. S. Johnson, M. Marschke, P. McConney, E. W. Pinkerton, and E. K. Wollengerg. 2009. Adaptive co-management for socialecological complexity. Frontiers in Ecology and the Environment 7(2):95-102. http://dx.doi.org/10.1890/070089

Asare, R., V. Afari-Sefa, Y. Osei-Owusu, and O. Pabi. 2014. Cocoa agroforestry for increasing forest connectivity in a fragmented landscape in Ghana. Agroforestry Systems 88(6):1143-1156. http://dx.doi.org/10.1007/s10457-014-9688-3

Barnes, M. L., J. Lynham, K. Kalberg, and P. Leung. 2016. Social networks and environmental outcomes. Proceedings of the National Academy of Sciences of the United States of America 113(23):6466-6471. http://dx.doi.org/10.1073/pnas.1523245113

Bellotti, E., L. Gaudalupi, and G. Conaldi. 2016. Comparing fields of sciences: multilevel networks of research collaborations in Italian academia. Pages 213-244 in E. Lazega and T. Snijders, editors. Multilevel network analysis for the social sciences. Methodos Series (Methodological Prospects in the Social Sciences), 12. Springer, Cham, Switzerland. http://dx.doi. org/10.1007/978-3-319-24520-1 9

Biber-Freudenberger, L., J. Ziemacki, H. E. Z. Tonnang, and C. Borgemeister. 2016. Future risks of pest species under changing climatic conditions. PLOS ONE 11(4):e0153237. http://dx.doi. org/10.1371/journal.pone.0153237

Bodin, Ö., and B. I. Crona. 2009. The role of social networks in natural resource governance: what relational patterns make a difference? Global Environmental Change 19(3):366-374. http:// dx.doi.org/10.1016/j.gloenvcha.2009.05.002

Bodin, Ö., A. Sandström, and B. Crona. 2017. Collaborative networks for effective ecosystem-based management: a set of working hypotheses. Policy Studies Journal 45:289-314. http://dx. doi.org/10.1111/psj.12146 
Bodin, Ö., and M. Tengo. 2012. Disentangling intangible socialecological systems. Global Environmental Change 22:430-439. http://dx.doi.org/10.1016/j.gloenvcha.2012.01.005

Borgatti, S. P., M. G. Everett, and L. C. Freeman. 2002. UCINET for Windows: software for social network analysis. Analytic Technologies, Cambridge, Massachusetts, USA.

Brailly, J., G. Favre, J. Chatellet, and E. Lazega. 2016. Market as a multilevel system. Pages 245-271 in E. Lazega and T. Snijders, editors. Multilevel network analysis for the social sciences. Methodos Series (Methodological Prospects in the Social Sciences), 12. Springer, Cham, Switzerland. http://dx.doi. org/10.1007/978-3-319-24520-1 10

Brennecke, J., and O. N. Rank. 2016. The interplay between formal project memberships and informal advice seeking in knowledgeintensive firms: a multilevel network approach. Social Networks 44(1):307-318. http://dx.doi.org/10.1016/j.socnet.2015.02.004

Chave, J., M. Réjou-Méchain, A. Búrquez, E. Chidumayo, M. S. Colgan, W. B. C. Delitti, A. Duque, T. Eid, P. M. Fearnside, R. C. Goodman, M. Henry, A. Martínez-Yrízar, W. A. Mugasha, H. C. Muller-Landau, M. Mencuccini, B. W. Nelson, A. Ngomanda, E. M. Nogueira, E. Ortiz-Malavassi, R. Pélissier, P. Ploton, C. M. Ryan, J. G. Saldarriaga, and G. Vieilledent. 2014. Improved allometric models to estimate the aboveground biomass of tropical trees. Global Change Biology 20(10):3177-3190. http://dx. doi.org/10.1111/gcb.12629

Davis, J. A. 1970. Clustering and hierarchy in interpersonal relations: testing two graph theoretical models on 742 sociomatrices. American Sociological Review 35:843-851. http:// dx.doi.org/10.2307/2093295

Dewees, P., F. Place, S. J. Scherr, and C. Buss. 2011. Investing in trees and landscape restoration in Africa: what, where, and how. Program on Forests (PROFOR), World Bank, Washington, D. C., USA. http://dx.doi.org/10.1596/26871

Dickison, M. E., M. Magnani, and L. Rossi. 2016. Multilayer social networks. Cambridge University Press, Cambridge, UK. http://dx.doi.org/10.1017/CBO9781139941907

Ghana Statistical Service. 2013. The 2010 population and housing census: regional analytical report - Ashanti region. Ghana Statistical Service, Accra, Ghana.

Govorushko, S. 2016. Human impact on the environment: an illustrated world atlas. Springer, New York, New York, USA. http://dx.doi.org/10.1007/978-3-319-24957-5

Gyau, A., M. Chiatoh, S. Franzel, E. Asaah, and J. Donovan. 2012. Determinants of farmers' tree planting behaviour in the northwest region of Cameroon: the case of Prunus africana. International Forestry Review 14(3):265-274. http://dx.doi. org/10.1505/146554812802646620

Hollway, J., and J. Koskinen. 2016. Multilevel bilateralism and multilateralism: states' bilateral and multilateral fisheries treaties and their secretariats. Pages 315-332 in E. Lazega and T. Snijders, editors. Multilevel network analysis for the social sciences. Methodos Series (Methodological Prospects in the Social Sciences), 12. Springer, Cham, Switzerland. http://dx.doi. org/10.1007/978-3-319-24520-1 13
Isaac, M. E. 2012. Agricultural information exchange and organizational ties: the effect of network topology on managing agrodiversity. Agricultural Systems 109:9-15. http://dx.doi. org/10.1016/j.agsy.2012.01.011

Isaac, M. E., L. C. N. Anglaaere, D. S. Akoto, and E. Dawoe. 2014. Migrant farmers as information brokers: agroecosystem management in the transition zone of Ghana. Ecology and Society 19(2):56. http://dx.doi.org/10.5751/ES-06589-190256

Isaac, M. E., B. H. Erickson, S. Quashie-Sam, and V. R. Timmer. 2007. Transfer of knowledge on agroforestry management practices: the structure of farmer advice networks. Ecology and Society 12(2):32. http://dx.doi.org/10.5751/ES-02196-120232

Isaac, M. E., and P. Matous. 2017 Social network ties predict land use diversity and land use change: a case study in Ghana. Regional Environmental Change 17:1823-1833. http://dx.doi.org/10.1007/ s10113-017-1151-3

Kadushin, C. 2012. Understanding social networks: theories, concepts, and findings. Oxford University Press, New York, New York, USA.

Kim, D. G., M. U. F. Kirschbaum, and T. L. Beedy. 2016. Carbon sequestration and net emissions of $\mathrm{CH}_{4}$ and $\mathrm{N}_{2} \mathrm{O}$ under agroforestry: synthesizing available data and suggestions for future studies. Agriculture, Ecosystems \& Environment 226:65-78. http://dx.doi.org/10.1016/j.agee.2016.04.011

Kongsager, R., B. Locatelli, and F. Chazarin. 2016. Addressing climate change mitigation and adaptation together: a global assessment of agriculture and forestry projects. Environmental Management 57(2):271-282. http://dx.doi.org/10.1007/s00267-015-0605$\mathrm{y}$

Koskinen, J., and T. Snijders. 2012. Simulation, estimation and goodness of fit. Pages 141-166 in D. Lusher, J. Koskinen, and G. Robins, editors. Exponential random graph models for social networks: theory, methods, and applications. Cambridge University Press, Cambridge, UK. http://dx.doi.org/10.1017/ CBO9780511894701.014

Levy, M. A., and M. N. Lubell. 2018. Innovation, cooperation, and the structure of three regional sustainable agriculture networks in California. Regional Environmental Change 18:1235-1246 http://dx.doi.org/10.1007/s10113-017-1258-6

Lusher, D., J. Koskinen, and G. Robins. 2012. Exponential random graph models for social networks: theory, methods, and applications. Cambridge University Press, Cambridge, UK. http://dx.doi.org/10.1017/CBO9780511894701

Malézieux, E., Y. Crozat, C. Dupraz, M. Laurans, D. Makowski, H. Ozier-Lafontaine, B. Rapidel, S. de Tourdonnet, and M. Valantin-Morison. 2009. Mixing plant species in cropping systems: concepts, tools and models: a review. Pages 329-353 in E. Lichtfouse, M. Navarrete, P. Debaeke, S. Véronique, and C. Alberola, editors. Sustainable agriculture. Springer, Dordrecht, The Netherlands, USA. http://dx.doi.org/10.1007/978-90-481-2666-8_22

Martin, A. R., and M. E. Isaac. 2015. Plant functional traits in agroecosystems: a blueprint for research. Journal of Applied Ecology 52:1425-1435. http://dx.doi.org/10.1111/1365-2664.12526 
Matous, P. 2015. Social networks and environmental management at multiple levels: soil conservation in Sumatra. Ecology and Society 20(3):37. http://dx.doi.org/10.5751/ES-07816-200337

Matous, P., and Y. Todo. 2015. Exploring dynamic mechanisms of learning networks for resource conservation. Ecology and Society 20(2):36. http://dx.doi.org/10.5751/ES-07602-200236

Matous, P., and Y. Todo. 2018. An experiment in strengthening the networks of remote communities in the face of environmental change: leveraging spatially distributed environmental memory. Regional Environmental Change 18:1741-1752. http://dx.doi. org/10.1007/s10113-018-1307-9

Matouš, P., Y. Todo, and D. Mojo. 2013. Roles of extension and ethno-religious networks in acceptance of resource-conserving agriculture among Ethiopian farmers. International Journal of Agricultural Sustainability 11:301-316. http://dx.doi. org/10.1080/14735903.2012.751701

Matous, P., and P. Wang. 2019. External exposure, boundaryspanning, and opinion leadership in remote communities: a network experiment. Social Networks 56:10-22. http://dx.doi. org/10.1016/j.socnet.2018.08.002

Mbow, C., P. Smith, D. Skole, L. Duguma, and M. Bustamante. 2014. Achieving mitigation and adaptation to climate change through sustainable agroforestry practices in Africa. Current Opinion in Environmental Sustainability 6:8-14. http://dx.doi. org/10.1016/j.cosust.2013.09.002

Munroe, J. W., and M. E.Isaac. 2014. $\mathrm{N}_{2}$-fixing trees and the transfer of fixed-N for sustainable agroforestry: a review. Agronomy for Sustainable Development 34(2):417-427. http://dx. doi.org/10.1007/s13593-013-0190-5

Niang, I., C. R. Oliver, A. Mohamed, A. Essel, C. Lennard, and J. Padgham. 2014. Africa. Pages 1199-1265 in P. Dube and N. Leary, editors. Climate change 2014: impacts, adaptation, and vulnerability. Part B: regional aspects. Contribution of Working Group II to the Fifth Assessment Report of the Intergovernmental Panel on Climate Change. Cambridge University Press, Cambridge, UK.

Nkamleu, G. B., and V. M. Manyong. 2005. Factors affecting the adoption of agroforestry practices by farmers in Cameroon. Small-Scale Forest Economics, Management and Policy 4 (2):135-148.

Nyantakyi-Frimpong, H., J. Kangmennaang, R. B. Kerr, I. Luginaah, L. Dakishoni, E. Lupafya, L. Shumba, and M. Katundu. 2017. Agroecology and healthy food systems in semihumid tropical Africa: participatory research with vulnerable farming households in Malawi. Acta Tropica 175:42-49. http:// dx.doi.org/10.1016/j.actatropica.2016.10.022

Pattison, P., and S. Wasserman. 1999. Logit models and logistic regressions for social networks: II. Multivariate relations. British Journal of Mathematical and Statistical Psychology 52 (2):169-193. http://dx.doi.org/10.1348/000711099159053

Pretty, J. 2003. Social capital and the collective management of resources. Science 302(5652):1912-1914. http://dx.doi.org/10.1126/ science. 1090847
Rico García-Amado, L., M. R. Pérez, I. Iniesta-Arandia, G. Dahringer, F. Reyes, and S. Barrasa. 2012. Building ties: social capital network analysis of a forest community in a biosphere reserve in Chiapas, Mexico. Ecology and Society 17(3):3. http:// dx.doi.org/10.5751/ES-04855-170303

Robins, G., and D. Lusher. 2012. Illustrations: simulation, estimation and goodness of fit. Pages 167-186 in D. Lusher, J. Koskinen, and G. Robins, editors. Exponential random graph models for social networks: theory, methods, and applications. Cambridge University Press, Cambridge, UK. http://dx.doi. org/10.1017/CBO9780511894701.015

Robins, G., P. Pattison, Y. Kalish, and D. Lusher, 2007. An introduction to exponential random graph $\left(p^{*}\right)$ models for social networks. Social Networks 29(2):173-191. http://dx.doi. org/10.1016/j.socnet.2006.08.002

Robins, G., T. Snijders, P. Wang, M. Handcock, and P. Pattison. 2007. Recent developments in exponential random graph $\left(p^{*}\right)$ models for social networks. Social Networks 29(2):192-215. http:// dx.doi.org/10.1016/j.socnet.2006.08.003

Schut, M., J. Rodenburg, L. Klerkx, A. van Ast, and L. Bastiaans. 2014. Systems approaches to innovation in crop protection: a systematic literature review. Crop Protection 56:98-108. http://dx. doi.org/10.1016/j.cropro.2013.11.017

Silici, L. 2014. Agroecology: what it is and what it has to offer. International Institute of Environment and Development, London, UK.

Sultan, B., P. Roudier, P. Quirion, A. Alhassane, B. Muller, M Dingkuhn, P. Cias, M. Guimberteau, S. Traore, and C. Baron, 2013. Assessing climate change impacts on sorghum and millet yields in the Sudanian and Sahelian savannas of West Africa. Environmental Research Letters 8(1):014040. http://dx.doi. org/10.1088/1748-9326/8/1/014040

Torquebiau, E., editor. 2016. Climate change and agriculture worldwide. Springer, Dordrecht, The Netherlands. http://dx.doi. org/10.1007/978-94-017-7462-8

Tubiello, F. N., M. Salvatore, S. Rossi, A. Ferrara, N. Fitton, and P. Smith. 2013. The FAOSTAT database of greenhouse gas emissions from agriculture. Environmental Research Letters 8 (1):015009. http://dx.doi.org/10.1088/1748-9326/8/1/015009

Vaast, P., and E. Somarriba. 2014. Trade-offs between crop intensification and ecosystem services: the role of agroforestry in cocoa cultivation. Agroforestry Systems 88(6):947-956. http://dx. doi.org/10.1007/s10457-014-9762-x

Valente, T. W. 1996. Network models of the diffusion of innovations. Computational and Mathematical Organization Theory 2(2):163-164. https://doi.org/10.1007/BF00240425

Vashum, K. T., and S. Jayakumar. 2012. Methods to estimate above-ground biomass and carbon stock in natural forests: a review. Journal of Ecosystem \& Ecography 2(4):116. http://dx.doi. org/10.4172/2157-7625.1000116

Wang, P., G. Robins, and P. Matous. 2016. Multilevel networks analysis using ERGM and its extension. Pages 125-143 in E. Lazega and T. Snijders, editors. Multilevel network analysis for 
social sciences. Methodos Series (Methodological Prospects in the Social Sciences), 12. Springer, Cham, Switzerland. http://dx. doi.org/10.1007/978-3-319-24520-1 6

Wang, P., G. Robins, and P. Pattison. 2009. PNet: program for the simulation and estimation of exponential random graph ( $\left.\mathrm{p}^{*}\right)$ models: user manual. Department of Psychology, School of Behavioural Science, University of Melbourne, Melbourne, Australia.

Wang, P., G. Robins, P. Pattison, and E. Lazega. 2013. Exponential random graph models for multilevel networks. Social Networks 35(1):96-115. http://dx.doi.org/10.1016/j.socnet.2013.01.004

Wood, B. A., H. T. Blair, D. I. Gray, P. D. Kemp, P. R. Kenyon, S. T. Morris, and A. M. Sewell. 2014. Agricultural science in the wild: a social network analysis of farmer knowledge exchange. PLoS ONE 9(8):e105203. http://dx.doi.org/10.1371/journal. pone. 0105203

Zappa, P., and A. Lomi. 2016. Knowledge sharing in organizations: a multilevel network analysis. Pages 333-353 in E. Lazega and T. Snijders, editors. Multilevel network analysis for the social sciences. Methodos Series (Methodological Prospects in the Social Sciences), 12. Springer, Cham, Switzerland. http://dx.doi. org/10.1007/978-3-319-24520-1_14 